\title{
Simulative STUDY OF NONLINEAR DYNAMICS IN SiNGLE STAGE BoOst CONVERTER
}

\author{
T. D. Dongale \\ Solid State Electronics and Computing Research Laboratory, \\ School of Nanoscience and Technology, \\ Shivaji University, Kolhapur (M.S), India
}

\begin{abstract}
The nonlinear dynamics such as bifurcation and chaos has got lot of attention in research fraternity. The power electronics is a dynamic and nonlinear field in which chaos plays an important role. The time dynamic and nonlinearity is cannot be neglected or it is default case in power electronics. The present paper discusses the simulative study of Bifurcation and chaotic behaviour in the single stage boost converter with the help of bifurcation diagram. It is also confer the parameter variation and its respective effect on bifurcation diagram and stability.
\end{abstract}

\section{KEYWORDS}

Bifurcation, Boost Converter, Chaos, Nonlinear Dynamics

\section{INTRODUCTION}

Looking at the age of science, it is all the time supposed that, deterministic system having predictable outcomes with considering initial condition constants or zero. But it was completely fall down when chaos come in to the game. The nonlinear phenomena and particularly chaos are intensively studied, investigated and implemented by many research groups [1-5]. The history of chaotic dynamics can be traced back to the work of Poincaré on celestial mechanics around 1900 $[1,6]$. In 1963 Lorenz give idea about simple nonlinear systems can have complex, chaotic behaviour [1]. The first version of chaotic behaviours in the electronics sphere of influence was described by Van der Pol in 1927 [7]. In 1980 Ballieul, Brockett and Washburn give the idea about chaotic behaviour in DC-DC converter [5]. The other researcher such as, Linsay and L. Chua's work on nonlinear circuits based on capacitor and diode is very famous one in the electronics [6, 8-9]. The Chua's diode is now famous with the name of 'Memristor' [10-12].

Recently the power converter topologies are very much investigated with single stage as well as multistage converter topology with respect to chaos and stability [13-17]. The power electronics is deals with the conversion and handling of large amount of power by means of electronics circuit. The conversion of power is in the form of AC-AC, AC-DC, DC-AC and DC-DC. The DC-DC converter is also known as chopper or DC amplifier. The linear and steady-state performance of converters and electric controls are investigated by conventional means [18-21], but nonlinear aspects and dynamic behaviour of converter is not studied and examined at its large. The present paper focus on the nonlinear dynamics of DC-DC boost converter with respect to bifurcation diagram and stability.

The rest of the paper is organized as follows, in the second section, the circuit operation of the boost converter briefly presented. In section III chaos and bifurcation phenomenon is briefly 
presented. Section IV reported the chaos and bifurcation phenomena under variation of selected circuit parameters such as Input supply voltage $\left(\mathrm{V}_{\mathrm{IN}}\right)$ and Load resistance $\left(\mathrm{R}_{\mathrm{L}}\right)$. In the last section conclusion is portrayed.

\section{BOOST CONVERTER}

Boost converter is also well known as step up DC-DC converter. It is mostly used where, output voltage required higher than that of input supply voltage e.g. power supply, motor control etc. The typical boost converter is shown in fig. 1. The circuit diagram consists of DC supply $\left(\mathrm{V}_{\mathrm{IN}}\right)$, Inductor (L), MOSFET as a switch, Diode (D), Capacitor (C) and Load resistance $\left(\mathrm{R}_{\mathrm{L}}\right)$. The output voltage is controlled by controlling the duty cycle of MOSFET. The circuit is operated is as follows, When MOSFET is on; the diode is reverse biased and hence it cut off the output stage. At this stage the inductor current increases linearly, in other words, inductor gets the energy from the supply and stores it, at this stage capacitor come into the picture, it discharges through load resistance. The next case, when switch is open the diode becomes forward biased and the output stage receives the energy from the inductor as well as the input. Thus the net energy transferred to the output from input is always greater in a given switching cycle. [22-23]

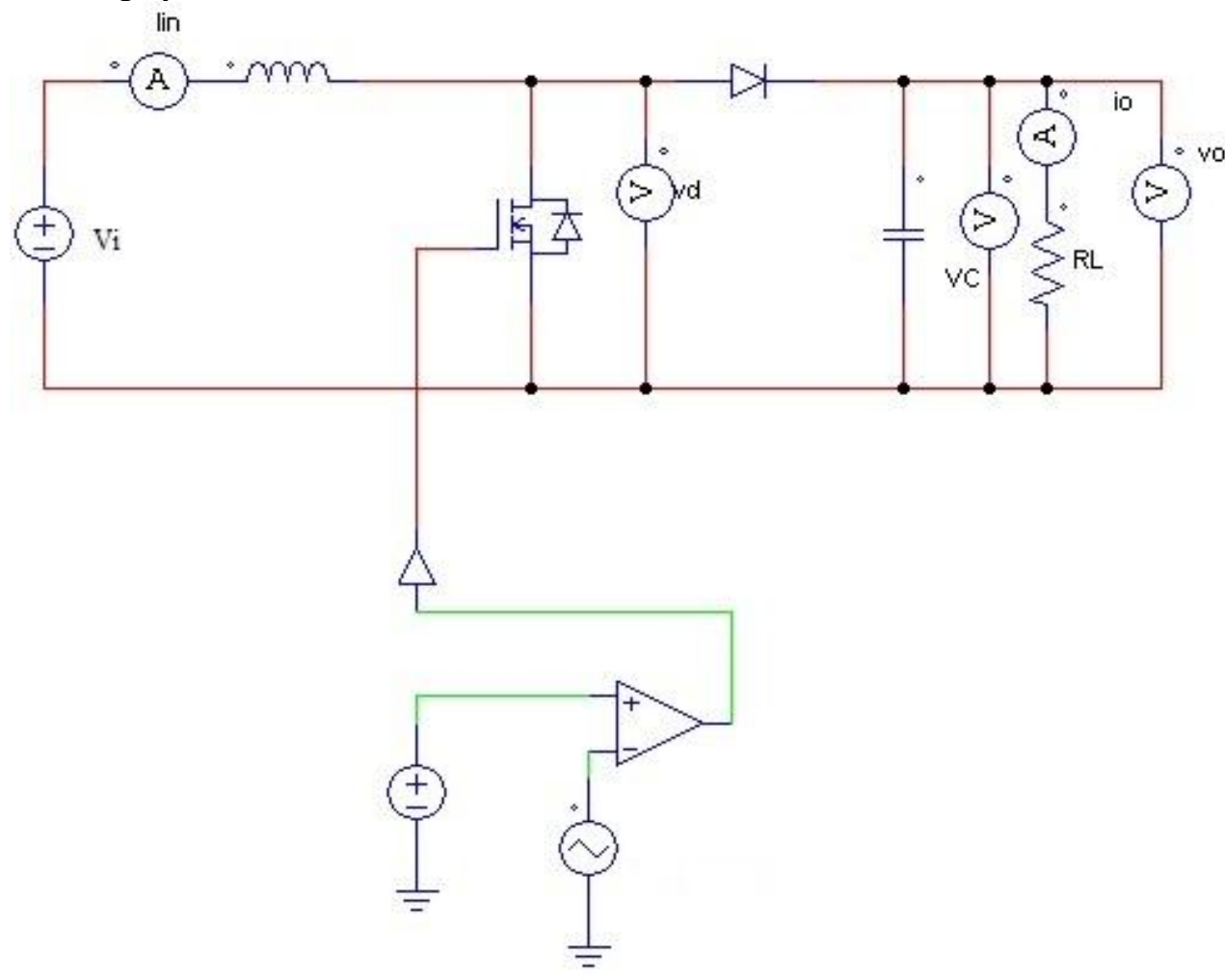

Figure 1: The DC-DC Boost converter. The circuit diagram consist of DC supply $\left(\mathrm{V}_{\mathrm{IN}}\right)$, Inductor in series (L), MOSFET as a switch, Diode (D), Capacitor $(C)$ and Load resistance $\left(\mathrm{R}_{\mathrm{L}}\right)$. (The simulation is carried out in the PSIM Software Environment)

\section{Chaos And Bifurcation Phenomena in Power Electronics}

The stability and linearity are two great forces for any real-time systems. The stability comes in a controlled environment but controlled environment is not possible in real time operations. Linearity or predictable behaviour is also not possible at any instant. We are assuming that the stable and linear behaviour of system is possible at controlled or constant initial condition, but 
question is appears when, initial conditions are changed. In this framework chaos is came into the picture. The chaos means unpredictable phenomena or instability, in which system give different results when some parameter is changed i.e. deterministic system, gives unpredictable outcomes. If you change any internal system parameter then system behaviour is changed qualitatively, it simply called as Bifurcation [3].

The power electronics is also faces the chaotic effect. The chaos is due to the switches; feedback and storage element such as capacitor, inductor and memristor; lumped as well as distributed [1112]. Bifurcation phenomena having two types, first is smooth bifurcation phenomena and other is border collision bifurcation phenomena. In smooth bifurcation, the system stability degrades without structural changes and in border collision bifurcation; the system stability degrades with structural change [24]. For controlling of chaos there are different methods are available in the literature such as, slope compensation method [25], modulated off-time current mode control technique [26], linear state-feedback control method [27], self-inductor current feedback method [28] and dynamic feedback control method [29].

\section{Study of Bifurcation Phenomena in Boost Converter}

Bifurcation theory was originally developed by Poincaré [3]. It describes the qualitative change in system behaviour when one or more parameters are changed. These system parameters are popularly known as system state variables. The state space variable and controlled variable graph is called as state control space. In this state control space, locations at which bifurcations occur are called bifurcation points $[3,13,30]$. Basically the boost converter is a nonlinear system and it having complicated steady state behaviour which some time called as chaos $[3,30]$. For study of bifurcation of single stage boost converter, the current through inductor $\left(\mathrm{I}_{\mathrm{L}}\right)$ is considered as state variable. The $\mathrm{I}_{\mathrm{REF}}$ is considered as a controlled variable $[3,30]$. The following figures show the variation of input voltage $\left(\mathrm{V}_{\mathrm{IN}}\right)$ and load resistance $\left(\mathrm{R}_{\mathrm{L}}\right)$ along with the corresponding effect on bifurcations diagrams of single stage boost converter.

\subsection{Variation of Input Voltages}

In this case the input voltage is varied and other parameters are kept fixed. The detail parameter declaration is depicts in table 1.

Table 1: Parameter for Case No- 1 (Variation of Input Voltage $V_{\text {IN }}$ )

\begin{tabular}{cll}
\hline Sr. No & \multicolumn{1}{c}{ Parameter } & Values \\
\hline 1. & Inductor (L) & $1 \mathrm{mH}$ \\
2. & Capacitor (C) & $5 \mu \mathrm{F}$ \\
3. & Load Resistance (RL) & $10 \Omega$ \\
4. & Switching Frequency (F) & $10 \mathrm{KHz}$ \\
\hline
\end{tabular}


a) $\quad \mathrm{V}_{\text {IN }}=5 \mathrm{~V}$

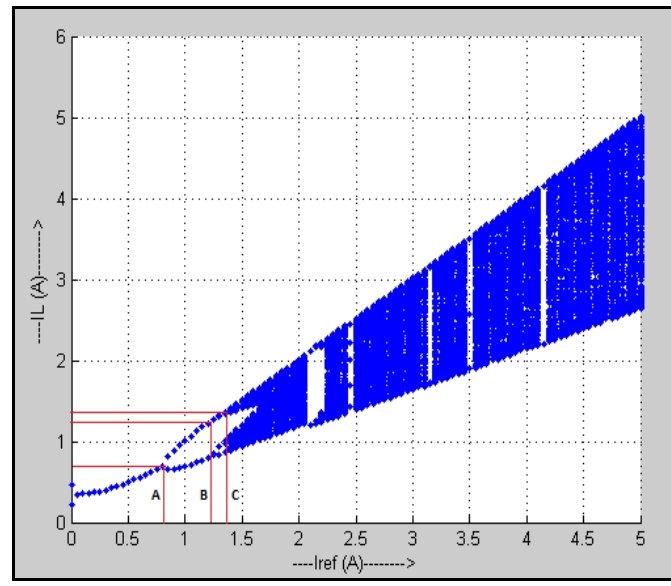

c) $\mathrm{V}_{\mathrm{IN}}=15 \mathrm{~V}$

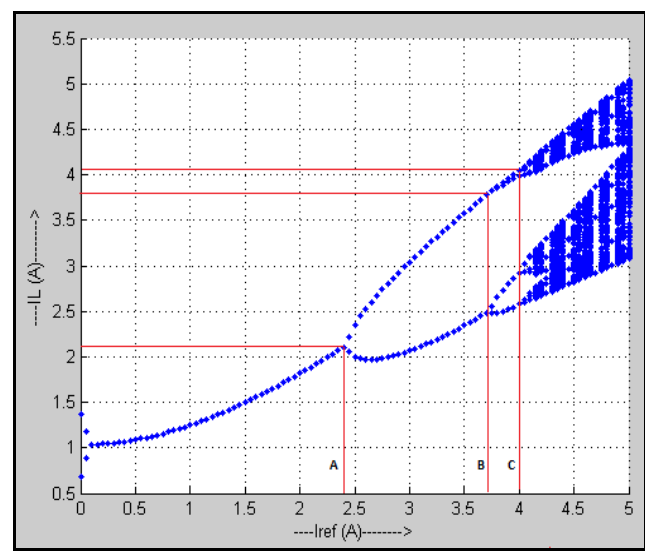

b) $\mathrm{V}_{\mathrm{IN}}=10 \mathrm{~V}$

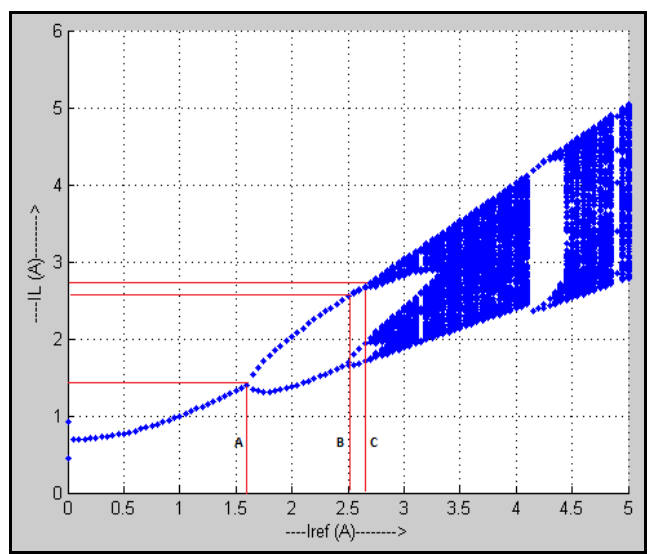

d) $\mathrm{V}_{\mathrm{IN}}=\mathbf{2 0} \mathrm{V}$

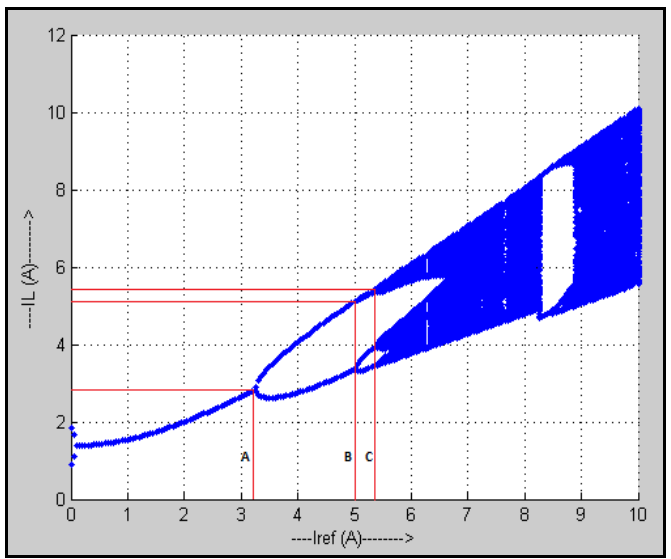

Figure 2 (a, b, c and d): Bifurcation diagram for Inductor Current $\left(\mathrm{I}_{\mathrm{L}}\right)$ with reference current $\left(\mathrm{I}_{\mathrm{REF}}\right)$ as the control Variable. Here the input voltage $\left(\mathrm{V}_{\mathrm{IN}}\right)$ is varied and other parameters are kept fixed. In this case current through inductor $\left(\mathrm{I}_{\mathrm{L}}\right)$ is considered as state variable and the reference current $\left(\mathrm{I}_{\mathrm{REF}}\right)$ is considered as a controlled variable. The graph of $\mathrm{I}_{\mathrm{L}}$ and $\mathrm{I}_{\mathrm{REF}}$ is called as state control space. The red solid line in the figure respect to $\mathrm{A}, \mathrm{B}$ and $\mathrm{C}$ represent the period- 1 bifurcation, period- 2 bifurcation and period- 3 bifurcation respectively.

\subsection{Variation of Load Resistances}

In this case the load resistance is varied and other parameters are kept fixed. The detail parameter declaration is depicts in table 2.

Table 2: Parameter for Case No- 2 (Variation of Load Resistance)

\begin{tabular}{rll}
\hline Sr. No & \multicolumn{1}{c}{ Parameter } & Values \\
\hline 1. & Inductor (L) & $1 \mathrm{mH}$ \\
2. & Capacitor (C) & $5 \mu \mathrm{F}$ \\
3. & Input Voltage (V) & $10 \mathrm{~V}$ \\
4. & Switching Frequency (F) & $10 \mathrm{KHz}$ \\
\hline
\end{tabular}


a) $\mathbf{R}_{\mathrm{L}}=15 \Omega$

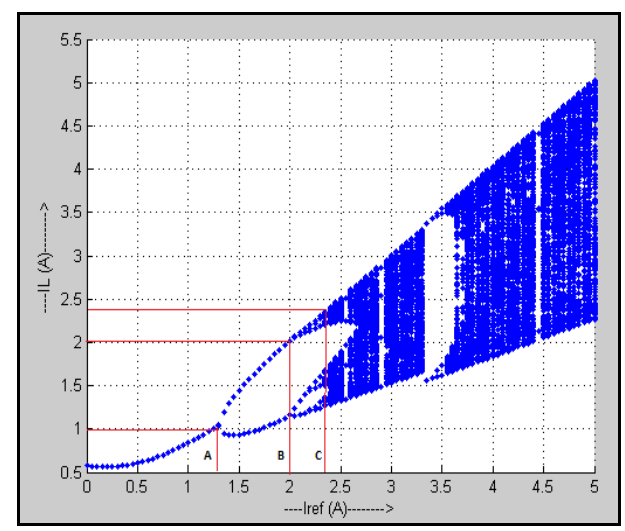

c) $R_{L}=25 \Omega$

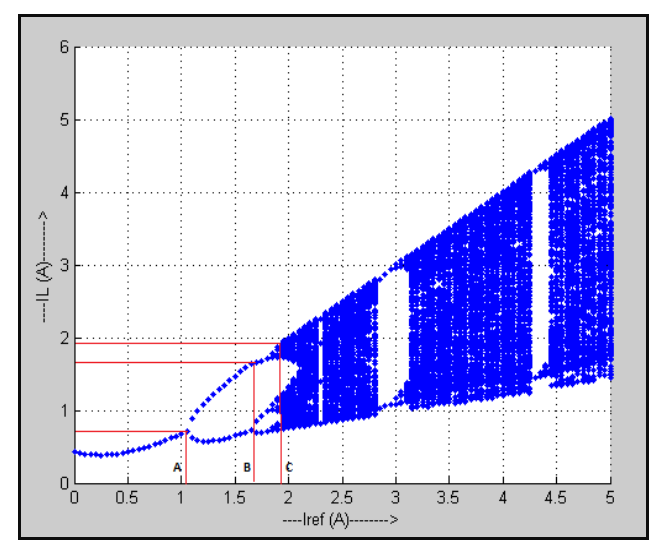

b) $\mathbf{R}_{\mathrm{L}}=\mathbf{2 0} \Omega$

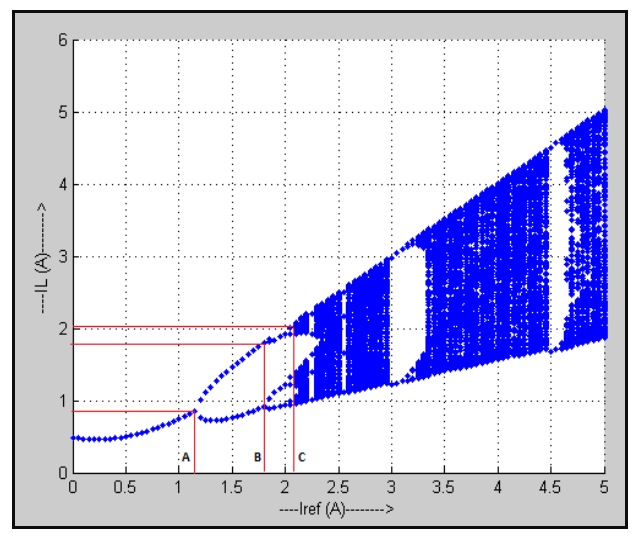

d) $\mathbf{R}_{\mathrm{L}}=\mathbf{3 0} \Omega$

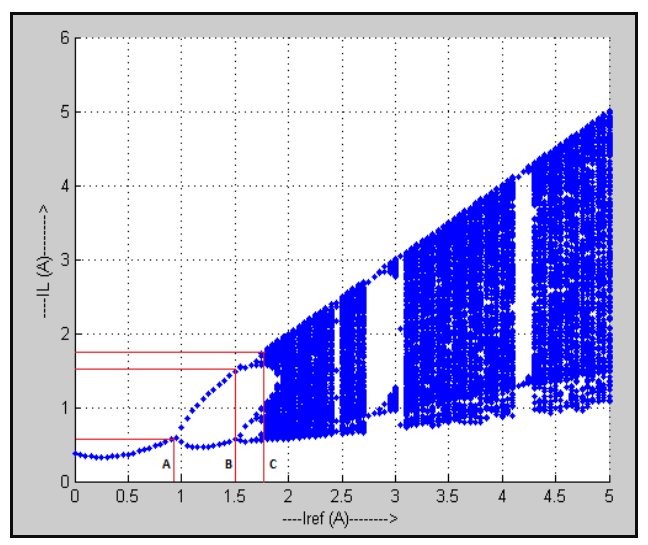

Figure 3 (a, b, c and d): Bifurcation diagram for Inductor Current $\left(I_{L}\right)$ with reference current $\left(\mathrm{I}_{\mathrm{REF}}\right)$ as the control Variable. Here the load resistance $\left(\mathrm{R}_{\mathrm{L}}\right)$ is varied and other parameters are kept fixed. In this case current through inductor $\left(\mathrm{I}_{\mathrm{L}}\right)$ is considered as state variable and the reference current $\left(\mathrm{I}_{\mathrm{REF}}\right)$ is considered as a controlled variable. The graph of $\mathrm{I}_{\mathrm{L}}$ and $\mathrm{I}_{\mathrm{REF}}$ is called as state control space. The red solid line in the figure respect to A, B and C represent the period- 1 bifurcation, period- 2 bifurcation and period- 3 bifurcation respectively.

\section{ANALysis OF Nonlinear Dynamics in BoOst CONVERTER With RESPECT TO PARAMETER VARIATION}

The fig. 2 and 3 (a, b, c and d) represent the bifurcation diagram for Inductor Current $\left(\mathrm{I}_{\mathrm{L}}\right)$ as a state variable and $I_{R E F}$ as the control Variable. The effect of supply voltage variations on bifurcation diagram is presented in the fig. 2 and the effect of load resistance variations on bifurcation diagram is presented in the fig.3. The supply voltage $\left(\mathrm{V}_{\mathrm{IN}}\right)$ is varied from $5 \mathrm{~V}$ to $20 \mathrm{~V}$ and corresponding effect is depicted in the same figures (fig.2). On the same ground, load resistance varied from $15 \Omega$ to $30 \Omega$ and corresponding effect is depicted in the same figures (fig.3). The red solid line A, B and C represent the period- 1 bifurcation, period- 2 bifurcation and period- 3 bifurcation respectively. It is clearly shown from above fig. 2, as the supply voltage $\left(\mathrm{V}_{\mathrm{IN}}\right)$ increases corresponding bifurcation points are also shifted in increment order and it become chaotic after period- 3 bifurcations in each case. It is found that from fig. 3 , as load resistance increases the period- 3 bifurcation point is shifted in decrement fashion. Hence for stable operation of boost converter, the load resistance should be minimum in the circuit. The table 3 
shows the numerical relationship between period-bifurcation and corresponding $\mathrm{I}_{\mathrm{REF}}$ and $\mathrm{I}_{\mathrm{L}}$ with variations of supply voltage $\left(\mathrm{V}_{\mathrm{IN}}\right)$.

Table 3: Relation between Period-Bifurcation and Corresponding $I_{R E F}$ and $I_{L}$ with Variations of Supply Voltage $\left(\mathrm{V}_{\mathrm{IN}}\right)$.

\begin{tabular}{clcc}
\hline $\begin{array}{c}\text { Supply } \\
\text { Voltage }\end{array}$ & Period-Bifurcation & $\mathbf{I}_{\mathbf{R E F}}$ in Amp. & $\mathbf{I}_{\mathbf{L}}$ in Amp. \\
\hline \multirow{3}{*}{$5 \mathrm{~V}$} & Period- 1 Bifurcation & 0.80 & 0.70 \\
& Period- 2 Bifurcation & 1.25 & 1.20 \\
& Period- 3 Bifurcation & 1.35 & 1.30 \\
\hline \multirow{3}{*}{$10 \mathrm{~V}$} & Period- 1 Bifurcation & 1.60 & 1.50 \\
& Period- 2 Bifurcation & 2.50 & 2.60 \\
& Period- 3 Bifurcation & 2.65 & 2.80 \\
\hline \multirow{3}{*}{$15 \mathrm{~V}$} & Period- 1 Bifurcation & 2.40 & 2.20 \\
& Period- 2 Bifurcation & 3.70 & 3.80 \\
& Period- 3 Bifurcation & 4.00 & 4.10 \\
\hline \multirow{2}{*}{$20 \mathrm{~V}$} & Period- 1 Bifurcation & 3.20 & 2.90 \\
& Period- 2 Bifurcation & 5.00 & 5.20 \\
& Period- 3 Bifurcation & 5.40 & 5.60 \\
\hline
\end{tabular}

It is clearly evident from table 3 , as the input supply voltage increases from $5 \mathrm{~V}$ to $20 \mathrm{~V}$ the Period- 3 Bifurcation point is also increasable shifted. The shifting of Period- 3 Bifurcation points means the chaotic behaviour of boost converter is also shifted. It is become unstable or chaotic system after Period- 3 Bifurcation points. These phenomena indicate the chaotic behaviour of boost converter in the presence of input voltage variations. The table 4 shows numerical details of period-bifurcation, reference current $\left(\mathrm{I}_{\mathrm{REF}}\right)$ and Inductor current $\left(\mathrm{I}_{\mathrm{L}}\right)$ with variations of load resistance $\left(R_{L}\right)$.

Table 4: Relation between Period-Bifurcation and Corresponding $I_{R E F}$ and $I_{L}$ with Variations of Load Resistance $\left(\mathrm{R}_{\mathrm{L}}\right)$

\begin{tabular}{clcc}
\hline $\begin{array}{c}\text { Load } \\
\text { Resistance }\end{array}$ & Period-Bifurcation & $\mathbf{I}_{\mathbf{R E F}}$ in Amp. & $\mathbf{I}_{\mathbf{L}}$ in Amp. \\
\hline \multirow{3}{*}{$15 \Omega$} & Period- 1 Bifurcation & 1.30 & 1.00 \\
& Period- 2 Bifurcation & 2.00 & 2.00 \\
& Period- 3 Bifurcation & 2.35 & 2.40 \\
\hline \multirow{2}{*}{$20 \Omega$} & Period- 1 Bifurcation & 1.15 & 0.90 \\
& Period- 2 Bifurcation & 1.70 & 1.85 \\
& Period- 3 Bifurcation & 2.10 & 2.05 \\
\hline \multirow{2}{*}{$25 \Omega$} & Period- 1 Bifurcation & 1.10 & 0.80 \\
& Period- 2 Bifurcation & 1.60 & 1.80 \\
& Period- 3 Bifurcation & 1.90 & 1.95 \\
\hline \multirow{3}{*}{$30 \Omega$} & Period- 1 Bifurcation & 0.90 & 0.60 \\
& Period- 2 Bifurcation & 1.50 & 1.50 \\
& Period- 3 Bifurcation & 1.70 & 1.80 \\
\hline
\end{tabular}

The table 4 shows the effect on period-bifurcation by variation of load resistance $\left(\mathrm{R}_{\mathrm{L}}\right)$. It is found that as a load resistance increase, the period-bifurcation points are decreasingly shifted towards origin value. The region above the period- 3 bifurcation is considered as a chaotic region of boost converter. The region above the period-3 bifurcation simply treated as an unstable region of boost converter in the case of load resistance variation. 


\section{Conclusions}

This paper presents study of nonlinear dynamic in the boost converter. The period-bifurcation diagram and chaotic effects are clearly seen in the fig. 2 and 3. It is clearly evident from the fig. 2 ( $a, b, c$ and d) and table 3 that for stable operation of any boost converter the input supply voltage must be high but in the permissible limit. It is also clearly indicate from the fig. 3 (a, b, c and d) and table 4 that for stable operation of any boost converter the load resistance must be minimum. The basic principle behind the boost converter is to boost the supply voltage hence there is some practical limitation in providing the supply voltage, but in the view point of stability consideration the keeping the load resistance minimum is the natural choice.

\section{REFERENCES}

[1] E.N. Lorenz, "Deterministic nonperiodic flow", J. Atmospheric Sciences, vol. 20, no. 2, pp. 130141, Mar. 1963

[2] R.M. May, "Simple mathematical models with very complicated dynamics", Nature, vol. 261, no. 5560, pp. 459-467, June 1976

[3] Ammar Nimer Natsheh, J. Gordon Kettleborough, Natalia B. Janson, Experimental study of controlling chaos in a DC-DC boost converter, Chaos, Solitons and Fractals (2007).

[4] M.P. Kennedy and L.O. Chua, "Van der Pol and chaos", IEEE Trans. on Circuits and Systems, vol. 33, no. 10, pp. 974-980, Oct. 1986

[5] J. Baillieul, R.W. Brockett and R.B. Washburn, "Chaotic motion in nonlinear feedback systems", IEEE Trans. On Circuits and Systems, vol. 27, no. 11, pp. 990-997, Nov. 1980.

[6] Hamill, David C. "Power electronics: A field rich in nonlinear dynamics." Proc. 3rd Int. Specialists Workshop on Nonlinear Dynamics of Electronic Systems NDES'95. 1995.

[7] B. van der Pol and J. van der Mark, "Frequency demultiplication", Nature, vol. 120, no. 3019, pp. 363-364, Sep. 1927

[8] P.S. Linsay, "Period doubling and chaotic behavior in a driven anharmonic oscillator", Phys. Rev. Letters, vol. 47, no. 19, pp. 1349-1352, Nov. 1981

[9] L.O. Chua, "The genesis of Chua's circuit", Archiv für Elektronik und Übertragungstechnik, vol. 46, no. 4, pp. 250-257, 1992

[10] Chua, L. O. Memristor - the missing circuit element, IEEE Trans. Circuit Theory, 18, 1971, pp.507-519.

[11] Dongale, T. D. "An Elementary Note on Skin Hydration Measurement Using Memristive Effect." Health (2013).

[12] Dongale, T. D. An Overview of Fourth Fundamental Circuit Element-'The Memristor', Available at: https://nanohub.org/resources/16590

[13] Cafagna D, Grassi G. Experimental study of dynamic behaviors and routes to chaos in DC- DC boost converters. Chaos, Solitons \& Fractals 2005; 25: 499-507.

[14] Tse CK. Flip bifurcation and chaos in three-state boost switching regulators. IEEE Trans Circuit Syst-11994; 41 (1) :16-21.

[15] Banerjee S. Nonlinear modeling and bifurcation in boost converter. IEEE Trans Power Electron $1998 ; 13$ (2) : 253-60.

[16] Abbasi A., Rostami M., Abdollahi J., Abbasi H. R. and Daneshmand H. N., "An analytical discrete model for evaluation the chaotic behaviour of boost converter under current control mode", ISIEA09 Malysia IEEE Conf., pp. 403-407, 2009.

[17] Guo L. W., Wei Z. L. and Ke W. J., "Self-Stable chaos control of dc-dc converter", Chinese Phys, Vol. 26, No. 3, pp. 30503-30506, 2009.

[18] Dongale, T. D., Jadhav, S. R., Kulkarni, S. V., Kulkarni, T. G., Mudholkar, R. R., \& Uplane, M. D. (2012). Performance Comparison of PID and Fuzzy Control Techniques in Three Phase Induction Motor Control. Int. J. on Recent Trends in Engineering and Technology, 7(2). DOI: 01.IJRTET.07.2.517

[19] Dongale, T. D., Kulkarni, T. G., Jadhav, S. R., Kulkarni, S. V., \& Mudholkar, R. R. (2012). AC Induction Motor Control-A Neuro-Fuzzy Approach. International Journal Of Engineering Science \& Advanced Technology, 2(4), 863-870. 
[20] Dongale, T. D., Kulkarni, T. G., Ghatage, S. R., \& Mudholkar, R. R. (2012). Implementation and Comparative study of Three Phase Induction Motor Control Using PID Controller, Fuzzy Logic and Neural Network Techniques, International Journal of Advanced and Innovative Research ISSN: 2278-7844, Volume 1, Issue 6, November 2012, pp. 271-275T.

[21] D. A. Kulkarni, T. D. Dongale and M. D. Uplane, Simulation of Three-Phase Inverter Using Minimum Number of Controlled Switches, Elixir Power Elec. Engg. 57 (2013), pp. 14071-14072

[22] B.K. Bose, Modern Power Electronics: Evolution, Technology and Applications, New York: IEEE Press, 1992

[23] Boost Converter, Available at: http://www.ee.iitb.ac.in/ sequel/sim_exercises/boost.pdf, Retrieved: 5 June, 2013.

[24] S. Banerjee, S. Parui, and A. Gupta, "Dynamical effects of missed switching in current-mode controlled dc-dc converters," IEEE Trans. on Circuit and System-II: Express Briefs, vol. 51, no. 12, pp. 649-654, Dec. 2004.

[25] C. K. Tse and Y. M. Lai, "Control of bifurcation in current-programmed DC/DC converters: a reexamination of slope compensation," in ISCAS, Geneva, Switzerland, 2000, pp. I-671-674.

[26] R. Giral, A. El Aroudi, L. Martinez-Salamero, R. Leyva, and J. Maixe, "Current control technique for improving EMC in power converters," Electronics Letters, vol. 37, no. 5, pp. 274-275, Mar. 2001.

[27] R. Leyva, L. Martinez-Salamero, H. Valderrama-Blavi, J. Maixe, R. Giral, and F. Guinjoan, "Linear state-feedback control of a boost converter for large-signal stability," IEEE Trans. on Circuit and System-I: Fundamental Theory and Applications, vol. 48, no. 4, pp. 418-424, Apr. 2001.

[28] K. Noppadol, S. Phaophak, and W. Theerayod, "Control of bifurcation for a current-mode DC/DC boost converter by self-inductor current feedback, , in ISCIT, Japan, 2006, pp. 200-203.

[29] W.-G. Lu, L.-W. Zhou and Q.-M. Luo, "Dynamic feedback controlling chaos in current-mode boost converter," Chinese Physics Letters, vol. 24, no. 7, pp. 1837-1840, 2007.

[30] Natsheh, Ammar N., J. Gordon Kettleborough, and Jamal M. Nazzal. "Analysis, simulation and experimental study of chaotic behaviour in parallel-connected DC-DC boost converters." Chaos, Solitons \& Fractals 39.5 (2009): 2465-2476.

\section{Author Bibliography}

Mr. T. D. Dongale was born in 1989, India. He did his Bachelors and Masters in Electronics specialized in Embedded Systems. He is Assistant Professor in School of Nanoscience and Technology, Shivaji University, Kolhapur. He also qualified the State Eligibility Test for Lectureship (SET) and National Eligibility Test for Lectureship with Junior Research Fellowship (NET-JRF) during his second year of Masters itself. He has been awarded 'Merit Scholarship' of the Shivaji University, Kolhapur for securing the first rank in his graduation and post graduation studies. Moreover he is also a recipient of the 'Eklavya Scholarship'

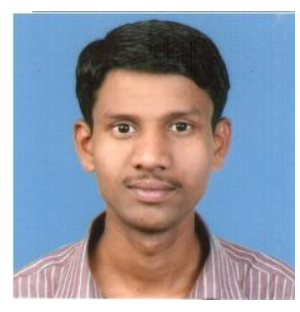
for supporting his Masters studies. He has to his credit 15 research papers published in reputed international journals and author of three book 'The Treatise on sensor interfacing' (Germany, Lap- Lambert, 2012)', 'Annals of Scholarly Research in Electronic', (Germany, Lap- Lambert, 2012)', 'ZigBee and RFID Based System Design', (Germany, Lap- Lambert, 2012)'. His current research interests are Soft Computing, Feedback Control System, Power Electronics, Computational Electronics, Chaos and Memristor. 